\title{
Multi-Disciplinary Optimisation Framework for Dual-Mode Launch Vehicle Concepts
}

\author{
Eleanor COLBECK ${ }^{1}$ and Cees BIL \\ School of Engineering, RMIT University, Melbourne, Australia
}

\begin{abstract}
Increasing demand for small satellite launch capability provides scope for the development of cost-efficient innovative payload delivery services. The advantages of air-launch capability are well-documented through the success of the Pegasus launch vehicle, but vertical ground-based takeoff is still the standard approach. This project details a transdisciplinary approach to designing a novel dualmode launch vehicle with air and ground launch capability, for small satellites. The vehicle's mission is determined to achieve a payload capacity of $50 \mathrm{~kg}$ to a $700 \mathrm{~km}$ sun-synchronous orbit. Alongside the vehicle design, potential carrier aircraft are assessed, and the interface between the two evaluated for feasibility. The proposed air-launch vehicle is a 3-stage HTPB solid rocket weighing just over 2.5t, with two $775 \mathrm{~kg}$ strap-on boosters for ground-launch. Both the air-launch and ground-launch solutions are verified with the launch optimiser program ASTOS. Future subsystem studies are proposed for further refinement.
\end{abstract}

Keywords. Nano Satellites, Launch Vehicles, Multi-Disciplinary Design, Modular Design

\section{Introduction}

The number of nanosatellites $(1 \mathrm{~kg}-10 \mathrm{~kg})$ and microsatellites $(10 \mathrm{~kg}-100 \mathrm{~kg})$ launched per year is growing due to increased commercial demand (Figure 1). Current studies predict the continuation of this trend well into the future [3]. The design of a new launch system requires many disperate requirements to be met and hence a transdisciplinary approach is required to obtain a balanced solution. These requirements are technical, economics and safety. Economical aspects are addressed by proposing a modular launch vehicle that can be ground launched or air launched as per customer requirements. This dual-mode solution offers flexibility and increases launch capability. Future concepts for cost reduction could be reusability of the first stage, e.g. by powered return or winged fly back. Safety is related to potential launch failure, inflight breakup and risk associated with falling debris. The technical challenges are in optimisation of the vehicle configuration to suit dual-mode options with a high level of commonality.

The majority of these satellites are used for Earth observation operating in Low Earth Orbit (LEO) [3]. Australia is well placed to benefit from participation in this growing sector of small satellite launch activity but is currently lacking infrastructure required for frequent launches to match the growing global demand.

\footnotetext{
${ }^{1}$ Corresponding Author, Mail: s3621610@student.rmit.edu.au.
} 


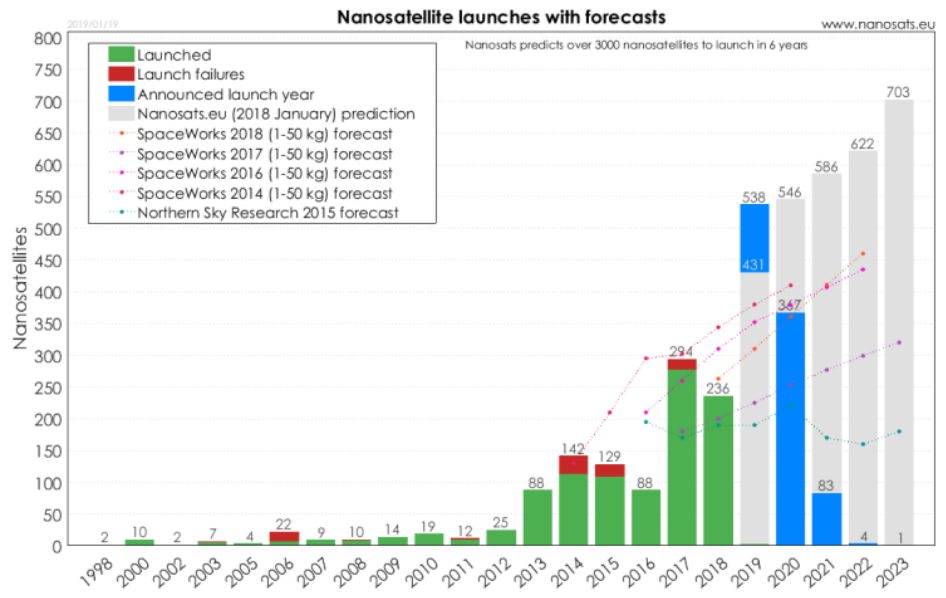

Figure 1: Predicted growth of nanosatellite launches [3].

Frequent and flexible launches of satellites up to $50 \mathrm{~kg}$ to LEO should be a preliminary goal for Australian space operations if the intent is to capitalise on the growing commercial space industry. Currently, Australia does not have a commercially accessible orbital launch pad. The development of the new Whalers Way Orbital Launch Complex is proposed and will undoubtedly be in high demand (Figure 2). An air-launch capable vehicle bypasses this, at least in a technical sense, by enabling takeoff from a standard runway; the orbital vehicle can then be launched from altitude at a remote location. It is anticipated that this flexibility will be essential for time-critical missions while the demand at Whalers Way is high. Other Australian launch sites are

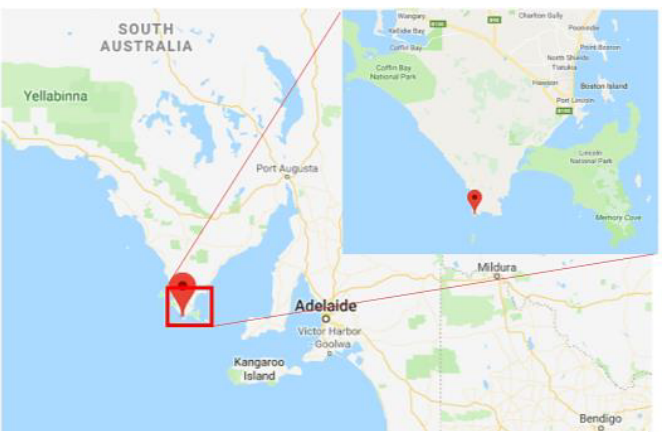

Figure 2: Whalers Way launch site location. also being considered, particular near the north coast.

Ground launches, however, are well understood and easily regulated. As air-launch operations add legislative complexity that may be a deterrent for some time, development of a ground-launch capability may be the priority. To address both of these needs a DualMode Launch Vehicle (DMLV), capable of launching from either a carrier aircraft or from a launchpad with minimal modification is proposed. The design of a new launch system requires many disparate requirements to be met and hence a transdisciplinary approach is needed to obtain a balanced solution. These requirements are technical, economics and safety. Economic aspects are addressed by proposing a modular launch vehicle that can be ground-launched or air-launched as per customer requirements. This dual-mode solution offers flexibility and increases launch capability. Future concepts for cost reduction could be reusability of the first stage, e.g. by powered return or winged fly back. Safety is related to potential launch failure, inflight breakup and risk associated with falling debris, which affects the choice of potential launch sites and flight paths. The technical challenges are in optimisation of the vehicle configuration to suit dualmode options with a high level of commonality. 


\section{Methodology}

The design of a launch vehicle encompasses a range of engineering disciplines, each discipline contributing to multiple parts and functionalities. At the conceptual design stage, these must all be considered simultaneously, as the properties of each part or system can have significant effects on another. French (2010) provides a summary of functional considerations in designing a generic launch vehicle, which helped guide the scope definition of the DMLV [1]. The other primary resource drawn upon in this process is the report published by Orbital (1993) detailing their transition from the Pegasus/B52 system to the Pegasus XL/Stargazer [2]. This report gives insight into the launch vehicle/carrier aircraft interface, and other unique design choices resulting from an airlaunch scenario. From these, a preliminary Functional Block Diagram (FBD) was generated to identify the areas of work and aid scope definition (Figure 3).

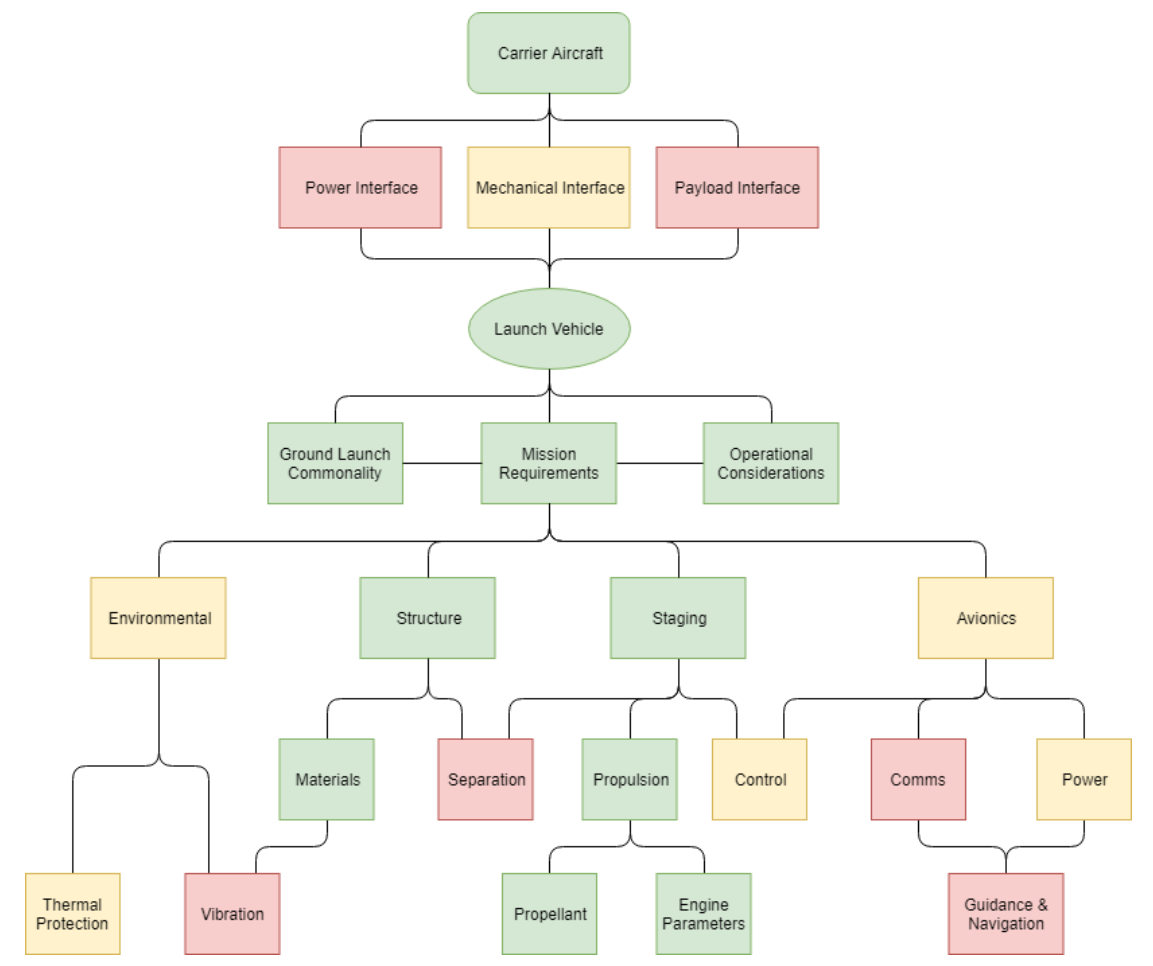

Figure 3: Functional Block Diagram illustrating the scope of the project.

The core design areas of the DMLV are highlighted green in Figure 2; these systems were identified to be most influential at this early stage. The engineering process, in this case, is structured around these key concepts, beginning with a representative mission definition and working down from a system level toward more granular subsystem design tasks. At this stage systems in yellow were considered insofar as their effect on the primary (green) systems. Red systems were disregarded, as their requirements are either driven by properties of primary systems or require resources disproportionate to their effect on the preliminary concept for analysis.

The DMLV design requirements stem from two key goals: to design a system capable of delivering $50 \mathrm{~kg}$ of payload into LEO from an air-launch, and to achieve the 
same objective from the ground with the same system, with minimum modification and modular design. A mission was designed to represent the desired capability of the vehicle, against which the success of the DMLV could be measured. Design, simulation and verification were all undertaken with the aim of completing this mission.

System requirements were defined in a trackable hierarchy, including explicitly defined requirements, such as the need for a $50 \mathrm{~kg}$ payload capacity, implicit requirements and requirements established by the target mission profile. Subsystem level requirements were defined in the same manner as the system-level requirements. A range of solutions for each subsystem, sourced from literature review and state of the art, were measured against the design requirements, and their results compared to identify the most viable solutions. Due to the iterative nature of launch vehicle design, many performance measures could not be quantifiably assessed in the first instance. Qualitative assessment of each solution's expected behaviour, informed by historical information, is the first measure of potential solutions. Solutions judged most feasible by the weighted design criteria were identified and used in system-level trade studies.

The most suitable subsystem solutions were combined to create three complete system concepts. The choice of which subsystems are combined was a balance of high scores against the design requirements and ensuring compatibility between components. With multiple concepts defined, a mass estimation for each was performed through optimal staging and ASTOS simulation. This was a critical step in ensuring that the chosen system was feasible before further design work was undertaken. The most promising system concept was verified with an iteration of mass budgeting using independent Mass Estimating Relationships (MERs). Projected increases in mass were adjusted conservatively, and the new system resized and revalidated. This validated system was then measured against the initial design requirements to ensure that the project goals were achieved.

\section{Mission definition}

The system level requirements were derived from the selection and definition of a commercially attractive mission, and guided by existing literature. To define what the DMLV should be capable of, the orbits of existing LEO satellites were analysed. The UCS satellite database provides an extensive list of satellites in Earth orbit [3]. This data was filtered to select only satellites with a launch mass $\leq 50 \mathrm{~kg}$ in LEO. Of these 582 satellites, 405 travel in a Sun-Synchronous Orbit (SSO) with very low eccentricity. This overriding majority, together with the fact that high-inclination orbits such as SSO require more $\Delta \mathrm{V}$ as they do not benefit from Earth's rotational velocity, suggests that the maximum-capability design point mission should target an SSO. The altitude and inclination capability of the vehicle was chosen from median orbital properties of these SSO satellites.

Following this process, the resulting proof of concept mission was a launch from Whalers Way (lat $-34.944^{\circ}$, long $135.626^{\circ}$ ), with a circular target orbit of $700 \mathrm{~km}$, at $98.6^{\circ}$. Air launch altitude and airspeed were subject to carrier aircraft performance. Given these targets, a $\Delta \mathrm{V}$ estimate of $10 \mathrm{~km} / \mathrm{s}$ was used as the initial design point. Later optimisation would converge on the true $\Delta \mathrm{V}$ requirement for each system concept. 


\section{Subsystem Analyses}

The results of the system requirements definition process guided the definition of subsystem requirements. A set of requirements was generated for each primary subsystem, derived from literature and the trickle-down of system-level requirements. Many of the requirements were at first stated and assessed qualitatively, and only quantitatively when relevant numbers could be applied from literature or without resource-intensive methods. This allowed a practical preliminary assessment of a large solution space, which was considered essential in a novel design project of this nature.

Subsystem requirements were then prioritised by the use of a pairwise comparison matrix as shown in Table 1. A score of "1" indicates the higher priority of the row's requirement over the intersecting column's requirement. The purpose of that matrix was to assign an importance weighting to each criteri for later assessment of design solutions.

Table 1: Pairwise importance ranking of air-launch stage propulsion subsystem requirements.

\begin{tabular}{|c|c|c|c|c|c|c|c|c|c|c|c|}
\hline & 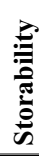 & 흔 & 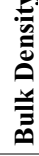 & 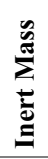 & 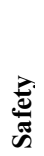 & $\overrightarrow{\underline{Z}}$ & 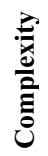 & $\overrightarrow{\tilde{\theta}}$ & 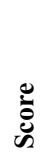 & $\begin{array}{l}\frac{\vec{b}}{00} \\
\frac{00}{20} \\
\theta^{\circ}\end{array}$ & 泀 \\
\hline Storability & & 1 & 1 & 1 & 0 & 0 & 0 & 1 & 5 & 13.9 & 4 \\
\hline $\mathbf{I}_{\mathrm{sp}}$ & 0 & & 0 & 0 & 0 & 0 & 0 & 0 & 1 & 2.8 & 8 \\
\hline Bulk Density & 0 & 1 & & 0 & 0 & 0 & 0 & 0 & 2 & 5.6 & 7 \\
\hline Inert Mass & 0 & 1 & 1 & & 0 & 0 & 0 & 1 & 4 & 11.1 & 5 \\
\hline Safety & 1 & 1 & 1 & 1 & 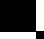 & 1 & 1 & 1 & 8 & 22.2 & 1 \\
\hline TRL & 1 & 1 & 1 & 1 & 0 & & 1 & 1 & 7 & 19.4 & 2 \\
\hline Complexity & 1 & 1 & 1 & 1 & 0 & 0 & & 1 & 6 & 16.7 & 3 \\
\hline Cost & 0 & 1 & 1 & 0 & 0 & 0 & 0 & & 3 & 8.3 & 6 \\
\hline
\end{tabular}

A comprehensive search for solutions was undertaken, looking at historically successful technologies as well as new and experimental ones. The merits and drawbacks of each solution were explored in the context of the previously stated requirements.

Finally, each of the solutions were scored independently against their subsystem's weighted selection criteria. Each solution was given a score of 1-3 against each requirement $i$, and the weighted total calculated.

The result of these analyses was a shortlist of preferred solutions to each of the vehicle's functions, summarised in Table 2.

Table 2: Summary of preferred subsystems.

\begin{tabular}{|c|c|c|c|}
\hline Subsystem & Component & Preferred Systems & Score \\
\hline \multirow{5}{*}{ Propulsion } & \multirow{3}{*}{ Upper stages } & 1. HTPB Composite & $98.1 \%$ \\
\hline & & 2. HTPB/N2O4 Hybrid & $73.1 \%$ \\
\hline & & 3. RP1/LOX & $70.4 \%$ \\
\hline & \multirow{2}{*}{ Ground stage(s) } & 1. HTPB Composite & $96.3 \%$ \\
\hline & & 2. RP1/LOX & $76.9 \%$ \\
\hline \multirow{6}{*}{ Structure } & \multirow{2}{*}{ Tanks/Casings } & 1. CFRP & $79.4 \%$ \\
\hline & & 2. Structural Steel & $61.9 \%$ \\
\hline & \multirow{2}{*}{ Fairing } & 1. CFRP & $69.1 \%$ \\
\hline & & 2. Maraging Steel & $69.1 \%$ \\
\hline & \multirow{2}{*}{$\begin{array}{l}\text { Unpressurised } \\
\text { Structures }\end{array}$} & 1. CFRP & $80.8 \%$ \\
\hline & & 2. Structural Steel & $59.0 \%$ \\
\hline \multirow{3}{*}{ Control } & & 1. Actuated fins & $89.8 \%$ \\
\hline & & 2. Thrust vanes & $67.6 \%$ \\
\hline & & 3. Engine gimbal & $66.7 \%$ \\
\hline \multirow{2}{*}{ Carrier Aircraft } & & 1. B757-200 & $86.9 \%$ \\
\hline & & 2. A330-200 & $82.1 \%$ \\
\hline
\end{tabular}




\section{Concept Generation}

A number of potential system configurations were developed through compatible combinations of the preferred technologies listed in Table 2.

The first design choice to be confronted here was the number of stages for each configuration. Recent studies have taken this idea beyond the purely physical problem and incorporated cost and complexity factors into multi-disciplinary optimisations (MDOs) of the optimal staging concept. For payloads of $50 \mathrm{~kg}$, three-stage configurations significantly outperform two-stage models in both Gross Take-Off Mass (GTOM) and cost [4]. Extending this concept to the DMLV, it follows that the ground launch configuration should consist of three stages. For a modular design, the air-launch configuration would then be a two-stage rocket, swapping the first ground launch stage for the carrier aircraft. However, studies addressing two-stage air launchers concluded that the use of a carrier aircraft does not provide as much $\Delta \mathrm{V}$ benefit as a rocket stage, and a two-stage air-launched vehicle is not economically feasible for launching to the target altitude [5].

These discoveries provided two options: reduce the target orbit's altitude or shift to a three-stage design. Reducing the vehicle's capabilities would reduce its usefulness, given how satellites have historically used LEO and SSO orbits. Moving to a three-stage configuration does increase the complexity and cost of the vehicle for the desired capability. However, given the DMLV's goal of modularity and flexibility, it is reasonable that the third stage could be discarded for lower target orbits, maintaining the two-stage cost advantage for suitably low-altitude missions. It was therefore decided that the three-stage approach would be taken to ensure vehicle capability was maintained.

Multiple system configurations were selected for further assessment, based on their subsystem scores and compatibility across subsystems.

\section{Concept Selection}

Preliminary performance comparisons were performed by estimation of each configuration's GTOM. Each configuration was sized with optimal staging and ASTOS simulation. The results given by this process are the GTOM of each configuration as a function of propellant and staging alone; these factors are so dominant in determining vehicle performance that it is unnecessary to compare auxiliary subsystems at this stage.

Beginning with each air-launch configuration, mass estimates were generated by application of an optimal staging algorithm [6]. Through iterative mass balance, the algorithm distributes propellant among each stage to achieve the $\Delta \mathrm{V}$ target $(10 \mathrm{~km} / \mathrm{s})$ at minimum vehicle mass. It takes stage $\mathrm{I}_{\mathrm{sp}}$ and IMF as inputs, which are properties of the propulsion system used and were sourced from literature. The effective payload used in the algorithm is the defined $50 \mathrm{~kg}$ payload, plus a $25 \%$ allowance for interfaces, plus the fairing mass as estimated by one of many MERs available for preliminary estimations of subsystem masses. This produced a simple estimate of propellant and dry mass of each stage. Using the known bulk density of propellants at their optimum mixing ratio, the volume of propellant in each stage was calculated. The diameter and length of each stage was then derived from the propellant volume, with the aim of maintaining high slenderness (length/diameter ratio) and constant diameter for all stages as far as possible.

This initial guess was provided as the representative ALV to run trajectory and sizing optimisations in ASTOS. The simulation was designed to optimise both the flight 
trajectory, given the Pegasus launch profile as an initial guess, and the size of each stage. Two optimisations were applied to each configuration; each optimisation is resource heavy and improvements were insignificant after the second pass.

Table 3: Comparison of DMLV system configurations, after optimisation.

\begin{tabular}{cccc}
\hline Property & $\begin{array}{c}\text { Configuration 1 } \\
\text { Mini-taur }\end{array}$ & $\begin{array}{c}\text { Configuration 2 } \\
\text { Top Scores }\end{array}$ & $\begin{array}{c}\text { Configuration 3 } \\
\text { Liquid Propulsion }\end{array}$ \\
\hline$\Delta \mathrm{V}(\mathrm{m} / \mathrm{s})$ & 8602 & 8697 & 8740 \\
Length $(\mathrm{m})$ & 7.76 & 7.34 & 7.71 \\
GTOM (kg) & 3865.6 & 2384.4 & 2249.9 \\
Payload \% & 1.293 & 2.097 & 2.222 \\
\hline
\end{tabular}

Of the three configurations assessed, the liquid-fuelled Configuration 3 is the most mass-effective, at just over 5\% lighter than the next-best Configuration 2. For a larger vehicle, this would be a great advantage, but for the DMLV this 5\% only translates to $135 \mathrm{~kg}$ of mass saved. Considering the operational and technical complexity involved in using cryogenic oxygen, this small mass saving cannot be considered significant enough to move away from a solid fuel solution. Configuration 2 was selected as the preferred system concept, and chosen as the basis for ground launch booster sizing.

\subsection{Ground booster selection}

The ground launch boosters were sized similarly to the air-launch stages, using optimal staging. The air-launch stages' mass and dimensions were fixed, and the booster configurations optimised in a ground launch scenario in ASTOS.

Table 4: Booster masses, ASTOS optimisation, pass 2

\begin{tabular}{|c|c|c|c|c|}
\hline Property & Serial HTPB & $\begin{array}{c}\text { Dual Parallel } \\
\text { HTPB }\end{array}$ & Serial RP1/LOX & $\begin{array}{c}\text { Dual Parallel } \\
\text { RP1/LOX }\end{array}$ \\
\hline$\Delta \mathrm{V}(\mathrm{m} / \mathrm{s})$ & 954 & 953 & 931 & 918 \\
\hline Length (m) & 1.99 & 2.84 & 2.24 & 3.15 \\
\hline GTOM (kg) & 3725.5 & 3715.7 & 3617.3 & 3614.5 \\
\hline
\end{tabular}

Table 4 shows the key dimensions of each booster configuration, with none of the configurations being significantly lighter. The GLV booster(s) will not be used in the vicinity of the crewed carrier aircraft, so are not subject to the same safety and storability constraints as the main ALV stages. As such, there is more scope to optimise the cost of the booster configurations.

HTPB propellant is an ITAR-restricted substance and as such pricing cannot be found [7]. However, the US Department of Defence publishes its standard price points for RP-1 and LOX. Assuming a mix ratio of 2.29 [8], the standard price per $\mathrm{kg}$ of the liquid bipropellant is $\$ 7.82$ [9]. Using the estimated propellant masses of Table 4, the price of each RP-1/LOX combination was found, and the breakeven price point for each HTPB configuration was found. These price points, and the corresponding total cost of booster propellant, are marked in Figure 4. 


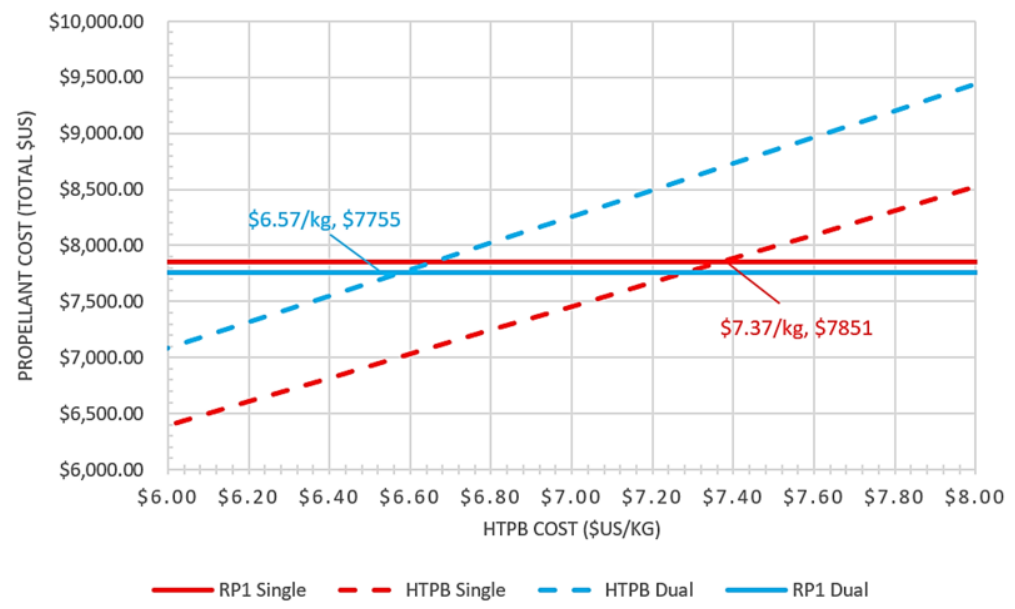

Figure 4: Cost breakpoints for HTPB and RP-1 booster configurations (RP-1 ref cost: US\$7.82/kg).

Figure 4 shows that HTPB propellant does not have to be substantially cheaper per $\mathrm{kg}$ than RP-1/LOX to be the more cost-effective solution in all cases. Given how extensively HTPB is referred to as one of the cheapest propellants available, it is reasonable to assume that it will surpass the breakeven prices. This is doubly true when accounting for the inert components; turbomachinery, cryogenic insulation and liquid engines are vastly more expensive than the simple solid rocket motor [1] [10].

The dual-HTPB configuration is evidently the cheapest, in terms of propellant. Further investigation is necessary to determine whether the cost advantage holds when accounting for inert components and structure. However, this configuration has several advantages: it maintains the control authority of the ALV first stage fins, has a higher Thrust-to-Weight ratio and adds the potential for modularity and operation flexibility. The dual HTPB booster was selected for the ground configuration.

\section{Final Concept Summary}

Table 5 and Figure 5 show the selected DMLV configuration. This configuration scores highly against the subsystem level requirements and has been proven feasible by ASTOS simulation.

Table 5: Selected DMLV configuration

\begin{tabular}{|c|c|c|c|c|c|c|}
\hline & & Booster & Stage 1 & Stage 2 & Stage 3 & Payload \\
\hline Propulsion & & $2 \times$ HTPB & HТPB & НТРВ & НTPB & - \\
\hline \multirow[t]{3}{*}{ Structures } & Casing & CFRP & CFRP & CFRP & CFRP & - \\
\hline & Unpressurised & CFRP & CFRP & CFRP & CFRP & CFRP \\
\hline & Fairing & & - & - & - & CFRP \\
\hline \multirow[t]{2}{*}{ Control } & Pitch/yaw & $\begin{array}{l}\text { Stage } 1 \\
\text { Fins }\end{array}$ & Fins & $\begin{array}{l}\text { Thrust } \\
\text { vanes }\end{array}$ & $\begin{array}{l}\text { Thrust } \\
\text { vanes }\end{array}$ & - \\
\hline & Roll & $\begin{array}{l}\text { Stage } 1 \\
\text { Fins }\end{array}$ & Fins & $\begin{array}{l}\text { Thrust } \\
\text { vanes }\end{array}$ & $\begin{array}{l}\text { Thrust } \\
\text { vanes }\end{array}$ & - \\
\hline TPS & & - & - & - & - & Ablator \\
\hline $\begin{array}{l}\text { Carrier } \\
\text { Aircraft }\end{array}$ & & B757-200 & - & - & - & - \\
\hline Average Score & & $\begin{array}{c}88.44 \% \\
\text { System Aver }\end{array}$ & $\begin{array}{l}87.47 \% \\
\text { Score: } 8\end{array}$ & $\begin{array}{l}78.70 \% \\
\%\end{array}$ & $78.70 \%$ & $74.95 \%$ \\
\hline
\end{tabular}


The final mass and dimensions of the DMLV are shown in Table 6, with an additional $100 \mathrm{~m} / \mathrm{s} \Delta \mathrm{V}$ as an allowance for drag on the booster and first stages. It is estimated that aerodynamic losses detract $40-160 \mathrm{~m} / \mathrm{s}$ of $\Delta \mathrm{V}$ from a ground-launch; an addition of $100 \mathrm{~m} / \mathrm{s}$ to the first ALV stage should be a conservative correction [11].

Table 6: Drag-corrected DMLV with dual-HTPB boosters.

\begin{tabular}{llcccccc}
\hline & Booster & Stage 1 & Stage 2 & Stage 3 & Payload & Total \\
\hline \multirow{4}{*}{ Mass } & Dry $(\mathrm{kg})$ & 88.0 & 198.4 & 47.4 & 8.3 & 75.5 & 505.7 \\
& Propellant $(\mathrm{kg})$ & 686.4 & 1709.4 & 401.3 & 68.5 & - & 3551.9 \\
& Wet $(\mathrm{kg})$ & 774.4 & 1907.8 & 448.7 & 76.7 & 75.5 & 4057.5 \\
& IMF & 0.114 & 0.104 & 0.106 & 0.108 & - & 0.125 \\
\multirow{5}{*}{ Dimensions } & Length $(\mathrm{m})$ & 2.99 & 4.04 & 1.16 & 0.49 & 0.95 & 6.64 \\
& Diameter $(\mathrm{m})$ & 0.43 & 0.58 & 0.58 & 0.33 & 0.9 & $1.44 m$ \\
& Slenderness & 7 & 7 & 2 & 1.5 & - & 4.61 \\
\multirow{5}{*}{ Engine } & Isp $(\mathrm{s})$ & 265 & 300 & 313 & 313 & - & - \\
& Thrust $(\mathrm{kN})$ & 58 & 70 & 20 & 5 & - & - \\
& Exit Area $\left(\mathrm{m}^{2}\right)$ & 0.13 & 0.26 & 0.26 & 0.086 & - & - \\
& Total $(\mathrm{m} / \mathrm{s})$ & 953 & 3357 & 3362 & 2078 & - & 9750 \\
& Proportion & $9.77 \%$ & $34.43 \%$ & $34.48 \%$ & $21.31 \%$ & - & $100 \%$ \\
\hline
\end{tabular}

This design was verified with ASTOS simulation, launching from both air and ground launch scenarios. Additionally, while stage masses were initially estimated from the empirically derived inert mass fraction, as a property of the propellant, a more granular mass estimation has since been undertaken. Structures, components and subsystem masses were estimated with a series of MERs. This second derivation of mass came in under the optimised estimate, suggesting that the optimised solution is both feasible and conservative, and further investigations are justified.

\section{Future Work}

The goal of this research is to define a framework for future development of a modular launch vehicle for small satellites. This paper, exemplifies the transdisciplinary nature of launch vehicle design. Some discussion on future studies are given below.

Development of an aerodynamics model

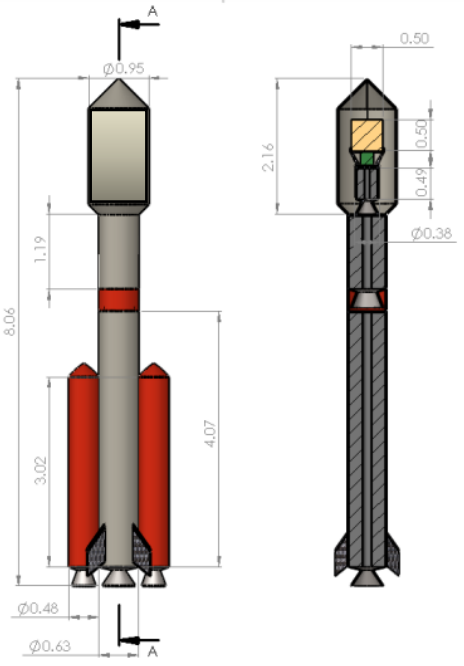

(a) Dimensions in meters

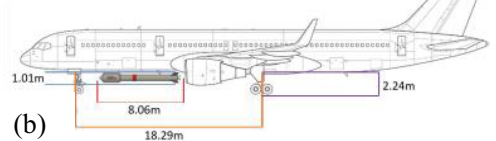

Figure 5: Selected DMLV in ground launch (a) and air launch (b) configuration. and simulation should be a high priority. ASTOS can simulate aerodynamic losses, moments and control, but not without a comprehensive study to inform the inputs required. Work performed here is a conservative approximation, but this is the most significant risk factor and will also be necessary for optimised sizing of stages and 
aerodynamic surfaces. A thorough trajectory analysis, including thrust and guidance optimisation, should go hand-in-hand with this.

The propulsion system has been defined very broadly but is one of the most complex subsystems. Further work should design the propellant grain composition, design and optimise the motor nozzle and, alongside the aerodynamics study, size the motor casing to minimise structural mass and aerodynamic drag while optimising propellant burn.

Structural design has been touched on in terms of key mass contributors, but there has been no detailed design of structural components. A future project should aim to produce fairing and fuselage geometry that can be verified with FEA and vibrational analysis. Particular focus should be put into bending loads incurred by wind shear, which will require the development of the aerodynamics study mentioned above.

\section{Conclusion}

This project has established the basis for the future development of a dual-capability air/ground launch vehicle, tailored to the unique needs of the exponentially growing small satellite launch market within Australia and beyond. The abstraction of the complex multi-disciplinary design task into a set of functionalities and system requirements enabled a comprehensive but resource-light exploration of the design space. From there, subsystem analyses brought the conceptual design into view. They defined it to a point where verification of the vehicle's success could be performed with simulations and more granular mass calculations. The result is a system framework designed to be built upon in a transdisciplinary manner, where multiple discipline specialists can combine their efforts toward achieving each of the system functions.

\section{References}

[1] J. R. French, Launch Vehicle Design, In R. Blockey et al. (eds.): Encyclopedia of Aerospace Engineering, John Wiley \& Sons, $1^{\text {st }}$ ed, Hoboken US, 2010, https://doi.org/10.1002/9780470686652.eae417.

[2] M. Mosier and E. Rutkowski, Pegasus XL Development and L-1011 Pegasus Carrier Aircraft, Orbital Sciences Corporation, Dulles US, 1993.

[3] Union of Concerned Scientists, 2019, UCS Satellite Database, Accessed 06.03.2019. [Online]. Available: https://www.ucsusa.org/nuclear-weapons/space-weapons/satellite-database

[4] C. Dupont, A. Tromba and S. Missonnier, New Strategy to Preliminary Design Space Launch Vehicle Based on a Dedicated MDO Platform, Acta Astronautica, Vol. 158, 2019, pp. 103-110.

[5] M. W. Van Kesteren, Air Launch versus Ground Launch: a Multidisciplinary Design Optimization Study of Expendable Launch Vehicles on Cost and Performance, TUDelft, Delft NL, 2013.

[6] I. Mallett, 2019, Multi-Stage Rocket Delta-V Optimizer, Accessed 10.05.2019. [Online]. Available: https://space.geometrian.com/calcs/opt-multi-stage.php

[7] The United States Munitions List, 22 CFR § 121.1, 2018.

[8] R. A. Braeunig, 2008, Basics of Space Flight: Rocket Propellants, Accessed 22.03.2019, [Online]. Available: http://www.braeunig.us/space/propel.htm

[9] Defense Logistics Agency, 2017, AEROSPACE ENERGY STANDARD PRICES FOR DOD CUSTOMERS EFFECTIVE 1 OCT 2017, Accessed 11.06.2019, [Online]. Available: https://www.dla.mil/Portals/104/Documents/Energy/Standard\%20Prices/Aerospace\%20Prices/E_2017 Oct1AerospaceStandardPrices 160829.pdf

[10] G. P. Sutton and O. Biblarz, Rocket Propulsion Elements, John Wiley \& Sons, $9^{\text {th }}$ ed, Hoboken US, 2017.

[11] N. Sarigul-Klijn, M. Sarigul-Klijn and C. Noel, Air-Launching Earth to Orbit: Effects of Launch Conditions and Vehicle Aerodynamics, Journal of Spacecraft and Rockets, Vol. 42, No. 3, pp. 569$575,2005$. 